\title{
The Influence of Autonomic Dysfunction Associated with Aging and Type 2 Diabetes on Daily Life Activities
}

\author{
Jerrold Petrofsky, Lee Berk, and Hani Al-Nakhli \\ Department of Physical Therapy, School of Allied Health Professions, Loma Linda University, Loma Linda, CA 92350, USA \\ Correspondence should be addressed to Jerrold Petrofsky, jpetrofsky@llu.edu
}

Received 5 August 2011; Revised 28 January 2012; Accepted 30 January 2012

Academic Editor: Nicola Montano

Copyright (๑) 2012 Jerrold Petrofsky et al. This is an open access article distributed under the Creative Commons Attribution License, which permits unrestricted use, distribution, and reproduction in any medium, provided the original work is properly cited.

\begin{abstract}
Type 2 diabetes (T2D) and ageing have well documented effects on every organ in the body. In T2D the autonomic nervous system is impaired due to damage to neurons, sensory receptors, synapses and the blood vessels. This paper will concentrate on how autonomic impairment alters normal daily activities. Impairments include the response of the blood vessels to heat, sweating, heat transfer, whole body heating, orthostatic intolerance, balance, and gait. Because diabetes is more prevalent in older individuals, the effects of ageing will be examined. Beginning with endothelial dysfunction, blood vessels have impairment in their ability to vasodilate. With this and synaptic damage, the autonomic nervous system cannot compensate for effectors such as pressure on and heating of the skin. This and reduced ability of the heart to respond to stress, reduces autonomic orthostatic compensation. Diminished sweating causes the skin and core temperature to be high during whole body heating. Impaired orthostatic tolerance, impaired vision and vestibular sensing, causes poor balance and impaired gait. Overall, people with T2D must be made aware and counseled relative to the potential consequence of these impairments.
\end{abstract}

\section{Introduction}

There is a natural senescence of the nervous system with aging $[1,2]$. This has a direct impact on autonomic function that has been observed in a number of different ways. For example, there is a reduction in endothelial cell function due to impairment in the release of vasodilator substances such as nitric oxide and prostacyclin [3-5]. This has the overall effect of reducing blood flow to all tissues in the body such as skin $[6,7]$, synapses [8], and neurons $[9,10]$. Impaired circulation and high levels of free radicals found in older people and people with diabetes [11-13] and glycosylation end products in the cells [14] cause reduced synaptic activity [8], neuronal death [3], and decreased baroreceptor response with age but little change in baroreceptor sensitivity [15]. When coupled with hardening of the arteries, this accounts for an increase in blood pressure, reduced orthostatic tolerance, and a general sluggishness in the autonomic nervous system to respond to environmental stressors associated with aging [15].

Type 2 diabetes exacerbates the normal senescence of the cardiovascular system with aging $[16,17]$. For example, when looking at the response to vascular occlusion, in relation to age, with greater age there is a reduction in the response of the circulation to vascular occlusion [18-20]. For individuals with diabetes, the reduction in blood flow with each year of age is the same but at a much lower baseline level. Thus, in many ways, the effect of aging and diabetes ar synergistic in reducing cardiovascular function with aging. However, there are also differences which will be discussed below. This paper will illustrate how autonomic dysfunction associated with aging and diabetes affects activities of daily life. The topics that will be reviewed are the response to local pressure, contrast baths, global heating, local heating, exercise, orthostatic tolerance, balance, and gait and how these are influenced by diabetes. All of these activities are common activities accomplished by individuals in their normal daily lives.

\section{The Vascular Endothelial Cell and Age and Diabetes}

At its simplest level, ageing and diabetes both cause damage to vascular endothelial cells in the body. Since blood vessels 
provide nutrients for neurons, synapses, and other tissues in the body, endothelial dysfunction has a major impact on the autonomic nervous system [21-24]. A major complicating factor is free radicals which also damage blood flow to tissues and increase both with ageing and diabetes [25]. Thus it is appropriate to start any discussion of autonomic damage and its effects on the body with a discussion of endothelial dysfunction.

In early stages of diabetes, the insulin receptor becomes defective on cells [26]. The defect is believed to be in the transduction after the binding of insulin to the activation of Phosphatidylinositol 3-kinase (PI3K) [27]. This signaling pathway is responsible for mediating the effect of insulin on the cell. In the vascular endothelial cell there are 2 competing pathways, both activated by insulin binding. The predominant pathway is the PI3K pathway [28]. This pathway activates the enzyme endothelial nitric oxide synthetase (ENOS). ENOS catalyzes the conversion of the amino acid L-Arginine to L-Citrulline producing, as a byproduct, nitric oxide [29]. Nitric oxide, in itself, is a free radical and causes relaxation in vascular smooth muscle. This causes an increase in blood flow in the skin and other organs as needed for metabolism, or as commonly seen in the skin, increasing heat loss from the body [30, 31].

In diabetes, the damage to the PI3K pathway is believed to be due to elevated blood glucose concentrations above $120 \mathrm{mg} / \mathrm{dL}[26,32,33]$. Evidence shows that spikes in glucose during a given 24-hour period also cause significant damage to the insulin transduction mechanism in the cells and may be more important than the average blood glucose [34, 35]. The exact relationship between these variations in blood glucose and endothelial dysfunction has not been clearly shown [32, 36-39]. Tissue studies have shown that, if 2 individual populations of cells are exposed to glucose, where the average glucose is the same but in one set of cells glucose fluctuates from highs to lows, there is more death of cells than in the population where glucose is just maintained high [35, 40-42]. Further, oxidative stress is much higher in the population subjected to spikes [42].

This mechanism itself reduces the transport of glucose into the cells under the control of insulin. Thus, cells shift to metabolism of free fatty acids to provide energy from metabolism for the cell. As free fatty acid metabolism increases, so do free radicals and the release of inflammatory cytokines $[43,44]$. These cytokines and free radicals damage the cell even further by both increasing insulin resistance through glycosylation end products, damaging the insulin receptor even further, and reducing the bioavailability of nitric oxide as a mediator of vasodilation [45]. High concentrations of free radicals in the cell have been shown to oxidize nitric oxide released from endothelial cells into a superoxide, peroxynitrite. This superoxide has no biological effect on vascular smooth muscle [37, 46, 47]. Further, in addition to nitric oxide eliciting vasodilation, a second vasodilator pathway in blood vessels, prostacyclin (prostaglandin $\mathrm{I}_{2}$ ) is also damaged by free radicals [48]. The reduced vasodilators in tissues cause vasoconstriction of the blood vessels to tissue, making the cells anoxic and releasing more free radicals [48]. This cyclic process accelerates and increases damage to cells over time until severe damage to the endothelial cells is seen.

A second pathway contributes to vasoconstriction well. As cited above, the main effect of insulin binding to the cells is activation of the PI3K pathway [49]. This pathway catalyzes the release of nitric oxide from cells so that as more glucose metabolism can take place, blood vessel dilation increases oxygen delivery and removes carbon dioxide from the increased metabolism in the cell. But, a competing pathway is also seen in the cell. Normally a minor pathway, the mitogen-activated protein kinase (MAPK) signaling pathway is activated in diabetes [50]. Whereas insulin causes vasodilation due to the PI3K pathway, it causes vasoconstriction in the MAPK pathway. The impairment in the PI3K pathways in diabetes shifts the effect of insulin, rather than causing vasodilation of blood vessels, to vasoconstriction, making the cell even more anoxic [50].

In addition to the increased vasoconstriction and increased free radicals in the cells associated with damage to the PI3K pathway and activation of the MAPK pathway, there are morphological changes in the endothelial cell. Normally, vascular endothelial cells have electrotonic connections to the surrounding vascular smooth muscles [46]. When endothelial cells increase their potassium permeability they hyperpolarize. As a result, these electrotonic connections to smooth muscle contribute to the relaxation of vascular smooth muscle [51,52]. This electrical connection aids in the hyperpolarization and relaxation of vascular smooth muscle to increase vasodilation. However, in Type 2 diabetes, these electrical connections are impaired $[17,51,53]$. Studies on rat retinal preparations of these gap junctions show that the principal gap junction protein, connexin 43 but not 37 and 40 is downregulated by incubation of these cells with high glucose media [54]. This may or may not pertain to vascular endothelial cells in the skin, but poses an interesting possibility.

Partially through glycosylation end products, and partly through impaired circulation (enhanced vasoconstriction), there is damage to the sympathetic nervous system that leads to a reduced blood flow response to stressors in organs such as the skin. Autonomic damage occurs to the sympathetic ganglia and neurons even at the time of the clinical diagnosis of diabetes [18,37, 55-60]. A common clinical measure of autonomic nervous system impairment is heart rate variability with the subject at rest. Normally, vasomotor rhythm in the sympathetic and parasympathetic systems causes the heart rate to vary continuously at rest $[6,37,61]$. These variations in heart rate can be seen by a frequency analysis of the EKG. As diabetes progresses, heart rate variability is reduced such that finally, sympathetic damage and parasympathetic damage have occurred to the extent that there is very little variation in heart rate with normal respiration or even a change in body position $[37,57,61]$. In addition, damage to tactile sensory nerves as well as to autonomic nerves in the skin contributes even more to the reduction in function seen in the autonomic nervous system [62]. 


\section{The Effect on Local Pressure}

The predominance of vasoconstrictors over vasodilators released from vascular endothelial cells in people with diabetes and older individuals causes skin blood flow to be lower at rest in people with diabetes than in age-matched controls compared to younger people [29]. Numerous studies have shown resting skin blood flow to be as little as one third (1/3) that of age-matched controls [56, 63-66]. Making matters worse, various protective mechanisms in the body at the level of the vascular endothelial cell are also damaged in diabetes. One of these is the response to local pressure. When standing on the feet, the pressure on the skin tends to impair the circulation. To prevent this, skin vertical pressure receptors are involved in eliciting vasodilation of the skin. When light pressure (up to $4 \mathrm{Kpa}$ ) is applied to the skin, there is an increase in skin blood flow [67-70]. When pressures as high as $22 \mathrm{Kpa}$ are applied to the skin, blood flow initially increases as pressure increases and then eventually by pressures of $22 \mathrm{Kpa}$ the blood flow is occluded [67, 70]. For a normal weight person standing on their feet, the pressure on the feet is approximately $15 \mathrm{Kpa}$ [42]. Thus, for the average person, skin blood flow increases as they stand increasing perfusion and protecting the skin of the feet from damage. The mechanism is largely related to nitric oxide release. It is not surprising, then, with impairment in nitric oxide pathways due to free radicals and damaged endothelial nitric oxide synthetase, that the pressure response is also reduced. In people with diabetes, pressures of only $4 \mathrm{Kpa}$ occlude most blood flow, and pressures of only $2 \mathrm{Kpa}$ cause a mild decrease in skin blood flow. Thus, by the time pressure reaches $7 \mathrm{Kpa}$, blood flow is totally occluded $[71,72]$. Thus, for the average individual of normal weight, what this means is that when standing, skin blood flow is occluded. For someone with diabetes, due to the usual higher incidence of obesity, pressures are even higher and can range to over $30 \mathrm{Kpa}$ on the skin of the feet and blood flow is absent from the skin during standing. This occlusion of the circulation during quite standing as well as during movement adds to possible circulatory damage, and, when lesions occur to the skin, healing is severely impaired [73].

An additional mechanism is that when pressure is removed from the skin, there is a large reactive hyperemia that washes out metabolites and restores oxygen supply [74]. This reactive hyperemia is not present in people with diabetes. Even when the pressure is removed recovery from the anoxia takes a much longer period of time $[74,75]$.

\section{Response to Occlusion}

Occlusion of the circulation occurs during normal daily activities. For example, at night, rolling on an arm or leg often results in occlusion of the circulation. This also occurs when changing body positions while sitting in a chair and leaning at various angles, or even, to some extent during exercise. Isometric exercise for example (to be discussed later) results in occlusion of the circulation in muscle during the exercise. Normally, as shown in Figure 1, the response to occlusion is, depending on the length of the

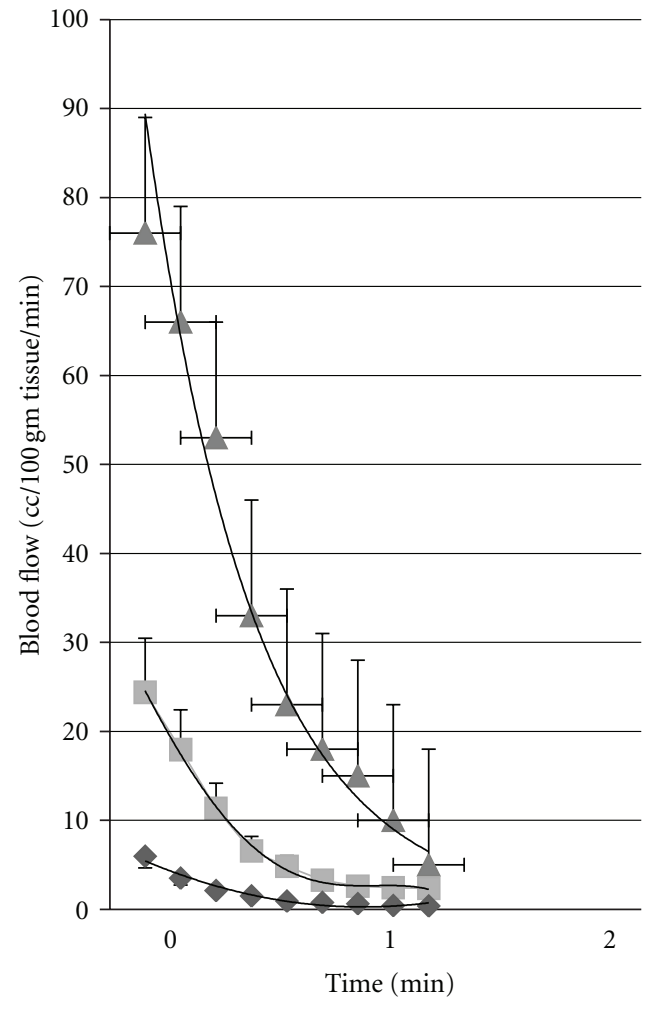

FIGURE 1: This figure shows the blood flow recorded for 2 minutes following the release of an arterial occlusion cuff on the brachial artery in young controls (triangle), nondiabetic age-matched controls (squares), and subjects with type 2 diabetes (diamonds). Illustrated here are the average results for 15 subjects in each group \pm standard deviation. Blood flows are expressed in $\mathrm{cc} / 100 \mathrm{~mL}$ muscle per minute and the time scale on the bottom is in minutes. Blood flows are recorded every 12 seconds starting at 3 seconds after occlusion (from [56]).

occlusion, a hyperemia after the blood flow is restored. The magnitude of the hyperemia in younger individuals can be very pronounced.

For example, for whole arm blood flows measured by volume plethysmography, resting blood flow normally averages 3 or 4 cc's per 100 grams tissue per minute. If occlusion is maintained for 4 minutes (a standard measure of vascular endothelial function used clinically) and then the occlusion is released, blood flow in a younger individual can increase to well over 75 cc's per 100 grams tissue per minute in the first few seconds, and then after 2 minutes return back to normal $[65,76]$. This exponential decrease in blood flow, as shown in Figure 1, is characteristic of younger individuals and, to a larger extent, older individuals. During the period that blood flow remains high, metabolites are washed from tissue and oxygen is rapidly restored protecting the tissue from damage and preparing it to return to normal activity $[19,26]$. In older individuals, as also shown in Figure 1, the magnitude of the reactive hyperemia is only 25 cc's per 100 grams tissue per minute. The hyperemia then, as was the case for younger individuals, returns within a few minutes back towards the normal resting blood flow. However, for 
people with diabetes, as shown in this figure, blood flow is barely above rest after the occlusion is removed even after 4 minutes of occlusion. After 2 minutes after occlusion, blood flow is restored once again to a level at about 25 or $30 \%$ that of the normal age-matched controlled individuals. These differences between the 3 groups of subjects was significant at all times from rest to 2 minutes postocclusive hyperemia (ANOVA $P<0.05)$. Recent evidence shows that nitric oxide is only a minor contributor to the mechanism for postocclusive hyperemia [77]. Thus, the reason it is impaired with ageing and diabetes is also only poorly understood. However, the clear effect of aging and diabetes can easily be seen in Figure 2. As shown in Figure 2, if the area under the entire 2 minute postocclusive curve in Figure 1 is calculated as a single number (excess blood flow needed after occlusion) and is plotted on a graph in relation to age, the top line in the figure shows the reduction in postocclusive hyperemia associated with the aging process. The second line on the figure, the squares, shows an equivalent line for people with diabetes starting at age 20 to age 80 . Over this age range, while the line is parallel to that of agematched controls, it is at several levels of magnitude lower showing the additional damage to occlusion caused in people with diabetes. However, if shear response is related to postocclusive hyperemia, it maybe mediated by a prostaglan-dinmediated mechanism.

\section{Local Heat}

The reaction of tissue to an increase in tissue temperature, like the reaction to skin pressure, is mediated by the vascular endothelial cell $[26,29,30]$. The blood flow increase associated with local heat is a biphasic response. There are 2 pathways involved. When heat above $42^{\circ} \mathrm{C}$ is applied to the skin, it immediately (phase 1) responds with a rapid increase in circulation. This increase in circulation is mediated by skin sensory nerves. The sensory nerves release substance-P and Calcitonin-gene-related peptide (CGRP) [78-82]. These substances diffuse laterally from the sensory nerves causing an increase in circulation by relaxing vascular smooth muscle around blood vessels. This protects the skin from rapid changes in temperature that might cause damage $[30,83]$. In skin tactile sensory nerves, TRPV1 voltagegated calcium channels are responsible for releasing these substances [84]. However, this is short lived. Skin sensory receptors accommodate and soon lose their ability to sustain vasodilation [50]. As they do, the skin vascular endothelial cells begin to release nitric oxide. Endothelial nitric oxide synthetase has a calcium-binding domain [29, 33, 35, 85]. Intracellular calcium, released by temperature sensitive ion channels in the cell membrane (TRPV4), activates the enzyme ENOS and thus elicits the production of nitric oxide in vascular endothelial cells $[26,86,87]$. In people with diabetes, as cited above, resting blood flow is much lower than in age-matched controls. Also, with the nitric oxide pathway being damaged through oxidation of nitric oxide [88] or lack of production of nitric oxide, or in some cases under bioavailability of L-Arginine as the precursor to nitric oxide in people with diabetes, the skin blood flow response

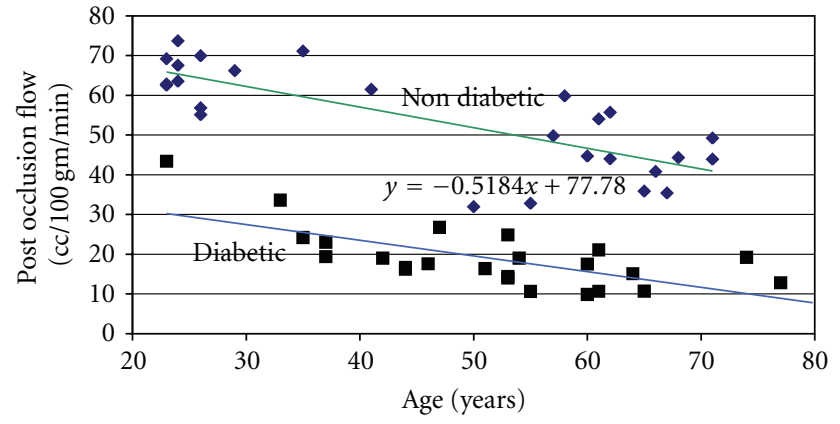

FIgURE 2: This figure illustrates the excess blood flow above rest during a two-minute period after the release of an occlusion cuff on the brachial artery of age-matched control subjects and subjects with diabetes. Individual data points are shown for control subjects (diamonds) and subjects with diabetes. For the control subjects the regression line was Blood Flow $=-0.518$ age +77.78 . For the subjects with diabetes the regression equation was Blood Flow = -0.253 age $+31.01[65]$.

is greatly diminished with heat [89-91]. Associated with diabetes are elevated levels of asymmetrical dimethylarginine (ADMA). This competes with l-arginine for a binding site on ENOS reducing production of nitric oxide form vascular endothelial cells [92]. Arginine supplements can compete with ADMA reducing endothelial dysfunction [92]. The impairment in skin blood flow with local heat in people with diabetes can be seen in Figure 3.

In Figure 3, when the skin blood flow response to heat at $42^{\circ} \mathrm{C}$ is examined, the blood flow response in people with diabetes is substantially lower than age-matched controls [93, 94].

This occurs in both the first and second phase of the blood flow response to heat. Even more interesting is the calories transferred through the skin. When the relationship between skin blood flow and heat gained by the skin in young, older, and subjects with type 2 diabetes is examined, it can be clearly seen that to warm the skin to the same temperature, people with diabetes take a fraction of the calories to warm the skin as is seen in either young subjects or age-matched controls $[63,64,89,96]$. One of the contributors to this is the fact that skin structure is also different in people with diabetes [97]. Thinner skin and more subcutaneous insulation impair the conductive heat loss through the skin to an applied thermal load. Skin thickness varies in different parts of the body. The thermal coefficient of the skin is much lower than that seen in age-matched controls without diabetes [97, 98]. The skin temperature rises faster in people with diabetes when a constant heat source is applied due to circulatory impairment. This, in turn, allows the skin to overheat. It is not surprising then that in Figure 4, it takes fewer calories in older people and people with diabetes to heat the skin.

The overall effect of this is that older people and people with diabetes are more susceptible to burns. Since the principal means of removing heat from the skin is the circulation when a warm heat source is applied [97], it is no surprise that people with diabetes are more susceptible to 


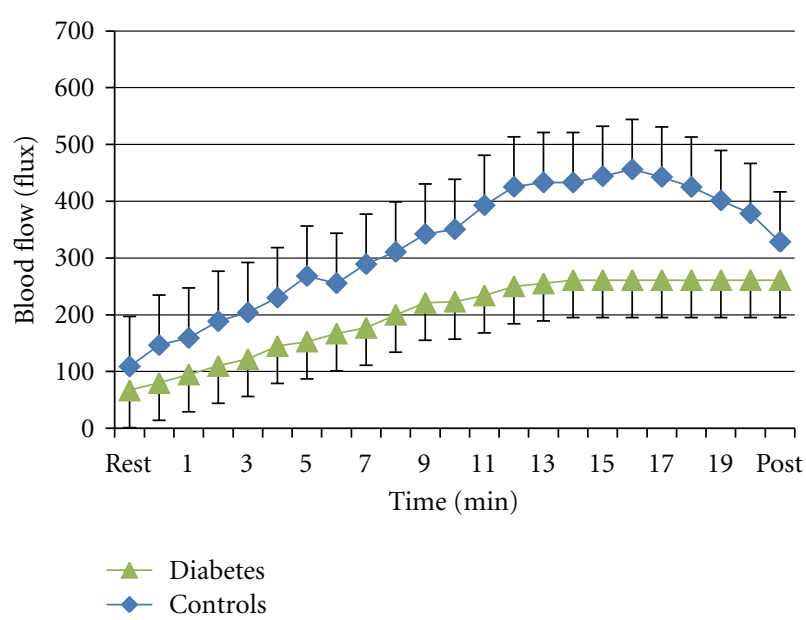

Figure 3: The blood flow response to a local heat source applied to the forearm in 10 subjects with diabetes and 10 age-matched controls over a 20 -minute period. Each point is the mean do 10 subjects \pm the SD (from $[71,95]$ ).

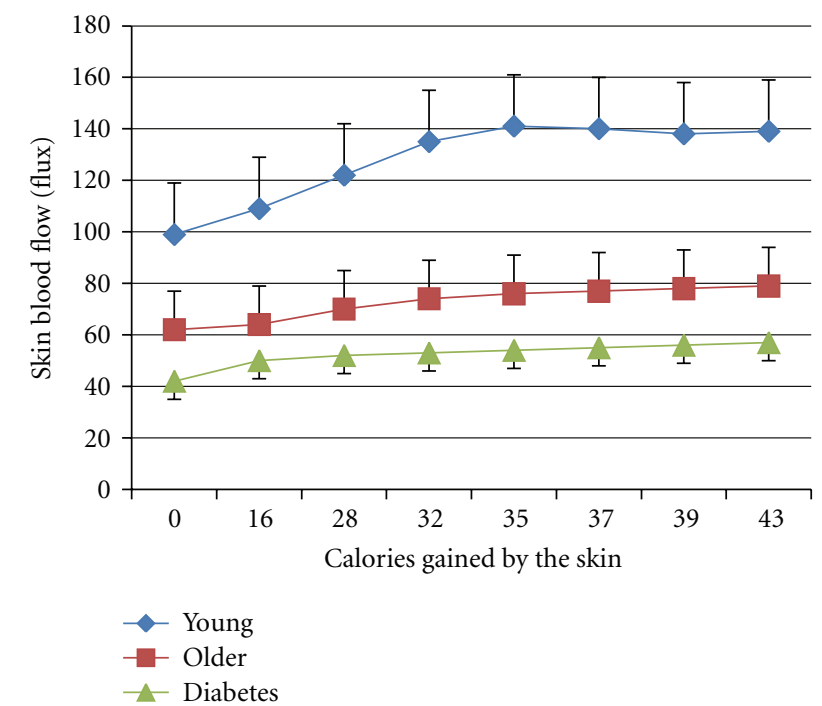

FIGURE 4: Illustrating the relationship between skin blood flow and heat gained by the skin in young subjects, older subjects, and subjects with type 2 diabetes. Average \pm the SD for each group is shown $(n=15)$. Experiments involved adding calories of heat to the skin by applying a brass 50 gram heated block at different temperatures and measuring the change in skin blood flow for a given caloric load $[99,100]$. The difference in heat absorbance between the 3 groups was significant (ANOVA $P<0.05$ ).

burns than are age-matched control subjects [101]. Another contributor to the poor thermal response of the skin in people with diabetes is drier skin. Skin moisture content is about half that of age-matched controls in people with diabetes [98]. When the skin is dry, the blood flow response to heat is less, presumably due to TRPV-4 osmotic receptor interaction with normal ENOS activation pathways [97, 98]. The same TRPV-4 channels that sense heat on endothelial cells also sense blood and skin osmolarity. When skin is dry, the channels show a diminished response to heat [102]. This is worse in people with diabetes. Even when a moist heat source is used on people with diabetes, the heat tolerance is still less for hot packs compared to age-matched controls $[97,98]$.

Another contributor to the diminished response of the skin to local heat is damage to sweat glands. Associated with diabetes, and to a much lesser extent aging, sweat glands have a reduced output and, in diabetes, are eventually destroyed [59]. This impaired pseudomotor response starts usually in the periphery such as the feet and then spreads throughout the body [18]. Since sweat glands are both apocrine and eccrine, it is not just the lack of sweat that becomes an issue for diabetes in that without adequate sweat the skin does not cool as fast, but since apocrine sweat glands provide oil for lubrication of the skin, the skin is even drier than that associated with aging [103].

\section{Contrast Baths}

Contrast baths are a good example of how impaired endothelial function impairs the response to heat. Beginning with the Greeks and Romans, contrast baths have been used in therapy $[6,104,105]$. The theory behind contrast baths is that by alternating hot and cold using a ratio of approximately 3 minutes in a hot bath to 1 minute in a cold bath, that there will be a greater increase in skin circulation than with a warm bath alone $[6,104]$. The enhanced blood flow response is alleged to cause greater removal of waste products from the skin than simple placement of the skin in a local warm bath [105]. When young subjects place their legs in contrast baths with a ratio of 3 minutes of warm to 1 minute of cold, the overall result is a much greater increase in skin blood flow than can be achieved by just leaving the leg in a contrast bath of the same temperature continuously. The oscillation in skin blood flow associated with placing the limb in alternating hot and cold baths compared to the sustained increase in blood flow with emersion of constant heat $[6,104]$. However, while this same phenomenon holds to a lesser extent in older individuals, in people with diabetes, contrast baths cause a smaller overall blood flow response in the skin than with a continuous warm bath. Thus for people with diabetes they provide a negative therapeutic effect. This is illustrated in Figure 5 (controls) and people with diabetes (Figure 6). Note the higher average blood flow above that of continuous heat in the age-matched controls but not in the subjects with diabetes [6].

\section{Global Heat}

The endothelial response to pressure, occlusion, and local heat shows a clear defect in the control of circulation. It is of no surprise then that when looking at more grandiose control where the sympathetic nervous system is needed to coordinate the body, the effects of age and diabetes are more pronounced. The response to global heat is mediated by the circulation and sweat. When subjects are exposed to a hot room, the sweat response is greatly diminished in older subjects compared to younger individuals [18]. The sweat rate is approximately $70 \%$ of that in age-matched controls. 


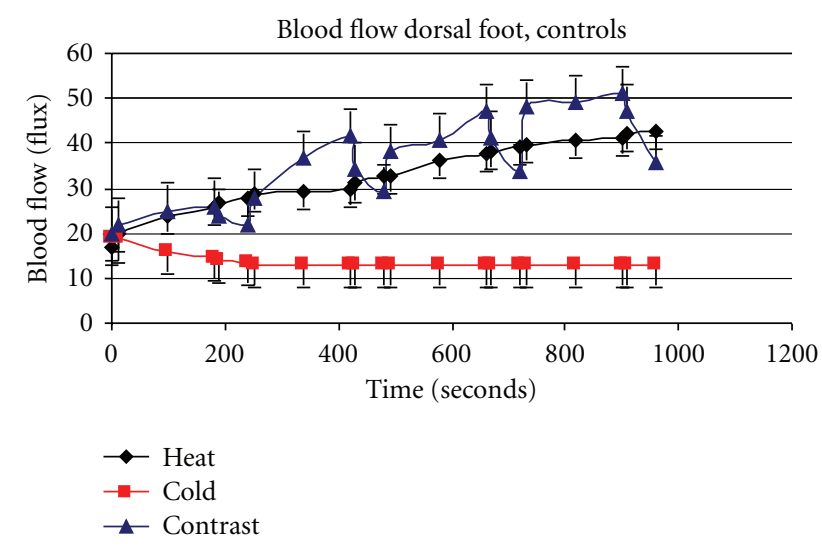

Figure 5: This figure illustrates the blood flow in the skin (flux) measured over the experimental period in control subjects during immersion in contrast baths (triangles), continuous heating (diamonds), and continuous cold immersion (squares). All data is the mean \pm the SD $[106,107]$.

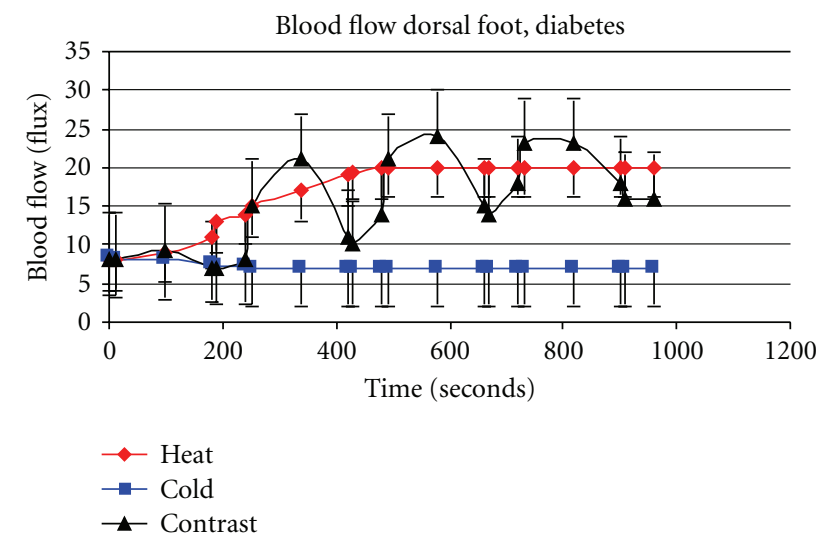

Figure 6: This figure illustrates the blood flow in the skin (flux) in subjects with diabetes during immersion in contrast baths (triangle), continuous hot (diamond), and cold immersion (squares) $[106,107]$.

It has been known for many decades that the sweat rate is lower and sweat gland density is lower in older compared to younger individuals [108]. When subjects are exposed to a hot room, the blood flow response is also greatly diminished compared to age-matched controls or younger individuals [18]. The lower resting skin blood flow due to age and lower blood flow response to heat, as was described above in the response to local heat, allows skin temperature to become elevated as is central body temperature in response to heat [108-111]. Plasma volume percent decrease during heat exposure was also greater in older than younger people [110]. It is not surprising that older individuals are more susceptible to hyperthermia as well [112]. Further, total sweat sodium loss increases with age [112].

Autonomic impairment, common in diabetes [24], alters both the blood flow response to global heat and the sweat response to global heat. Numerous studies have shown that people who have diabetes have impaired response to whole body (global) heating $[59,113,114]$. At rest, the lower resting skin blood flow lowers skin temperature compared to agematched controls [115]. But when subjects are exposed to a hot room, the blood flow response and sweat response are greatly diminished compared to age-matched controls or younger individuals $[18,26]$. The reduced sweat rate in people with diabetes is related to low nitric oxide production in sweat glands and high concentrations of free radicals in the blood [116]. This same study related autonomic nerve dysfunction to this same concentration of high free radicals [116]. These investigators show that Glutathione, a potent antioxidant in cells, is generally depleted in people with diabetes [117] and may allow enhanced nitric oxide production to increase free radicals in the cells and lead to autonomic neuropathy. Because of impairment in sweating, skin temperature is elevated far above that seen in younger or older individuals as is rectal temperature [118].

\section{Orthostatic Tolerance}

Blood pressure is normally well regulated in the body. Changes in posture usually cause a small and transient change in blood pressure $[119,120]$. The most common test is the head up tilt test to $70^{\circ} \mathrm{C}$ [121]. If blood pressure drops more than $20 \mathrm{mmHg}$ for 1 minute after going from a seated to standing position, the World Health Organization classifies this as orthostatic intolerance [122]. Orthostatic tolerance can also be measured by measuring the blood pressure response to standing from a seated position or from a lying position. A more radical stress is by having someone squat and then stand $[119,120]$. Another laboratory-based measure is to use lower body negative pressure to induce a change in blood pressure [123]. Aside from the obvious risk of falling in the elderly, orthostatic hypotension is associated with cardiovascular mortality and all-cause mortality [124]. Orthostatic tolerance decreases with both age and diabetes [125-128].

Normally when standing upright there is decreased blood pressure, and as the autonomic nervous system compensates, the blood pressure comes back towards normal $[122,129]$. This is achieved by an increase in peripheral vasoconstriction and an increase in heart rate. In older people and people with diabetes, there is a reduction in heart rate variability caused by reduced control of both the sympathetic and parasympathetic nervous systems $[130,131]$. It is of no surprise then that orthostatic tolerance is also reduced in older people and people with diabetes due to loss of autonomic control. In many people with diabetes, we have observed no change in heart rate when changing body position $[132,133]$. The reduced heart rate variability shows impairment in autonomic function in these groups [130]. Some of the deficit in autonomic function has been linked to ganglionic damage [134]. Autonomic neuropathy is also common with age and diabetes [135]. There is some evidence that there is reduced baroreceptor sensitivity with ageing and diabetes possibly due to increased angiotensin II activity due to increased renin release form the kidney [136]. 
In people with diabetes, in many studies, there is conventionally about $25 \%$ of the population that have orthostatic tolerance defined by the World Health Organization. However, in recent studies, we found that if the room is first warmed to $39^{\circ} \mathrm{C}$ and subjects are warmed in the room for 20 minutes, upon standing, $100 \%$ of the people had orthostatic intolerance [122]. This has been confirmed in other studies [123, 137]. Thus, it appears that when stressors are combined, the autonomic nervous system cannot handle the combined load of a thermal stress and an orthostatic stress together, and all people with diabetes seem to have orthostatic intolerance. In younger controls, there is enough reserve in the cardiovascular system to accommodate 2 simultaneous stressors.

\section{Isometric Exercise}

Isometric exercise is a type of exercise where force is exerted by the muscle but the muscle does not change length [138, 139]. With impaired neurogenic control of the circulation in muscle, impaired local control of the circulation and impaired sweating, the cardiovascular response to isometric exercise is also impaired in people with type 2 diabetes compared to age-matched controls [59, 140]. For example, looking at endurance and recovery of endurance, if 2 isometric contractions are accomplished 10 minutes apart, the endurance for the first contractions is similar in an agematched control group than in people with diabetes [141, 142]. However, for the second contraction the endurance in the group of diabetes is much shorter showing a prolonged recovery time, and when blood flow is measured lower blood flows are found during and after exercise in people with diabetes compared to age-matched controls [59, 140]. During the exercise, traditionally blood pressure increases (both systolic and diastolic) driven by high sympathetic outflow. In people with diabetes, resting blood pressure is higher as is the blood pressure response to the exercise. Since the heart rate change and heart rate variability are both reduced with ageing and diabetes, the higher blood pressure response is driven by higher total peripheral resistance, increasing stroke work considerably [142-144]. Sympathetic impairment also reduces the sweating response to isometric exercise [59]. For dynamic exercise, strength is generally less and endurance is less for either kinetic or dynamic exercise. Thus, for people with diabetes, exercise performance and the cardiovascular responses are both affected by diabetes.

\section{Balance}

One of the most pronounced effects of diabetes is on balance and gait. Balance and gait are both contributed to by the vestibular system, the eyes, and proprioceptive system in the legs $[57,145]$. All 3 are important in allowing someone to balance themselves and to walk properly. With diabetes, with diabetic polyneuropathies, there is impaired vestibular function, impaired vision due to retinopathies, and impaired somatosensory input into the vestibular nuclei [57]. It is of no surprise then that there are balance impairments in people with diabetes. During quite standing and during movement balance is impaired [146, 147]. Incorrect visual cues simply make matters worse. Thus, in dim light, poor visual cues make balance even worse in people with diabetes [148]. People with diabetes have better balance in a totally dark room because they do not confuse incorrect visual cues and hamper their ability to balance. Further, the color of light seen by the eyes shows the greatest impairment with diabetes in the blue range, the very color that most night lights are [148]. In another study, the autonomic response to balance is also impaired in people with diabetes. Thus, for people with diabetes, there is an abnormally low heart rate and blood pressure response to allow the body to be maintained stable during balancing attempts, making balance even worse [26].

These all have a pronounced impact on gait. In general, people with diabetes, because of lack of feeling and proprioceptive sense and poor balance, have slower gait and maintain a wider balance for postural support during gait. Further, during gait they circumduct thus having the legs further apart to be able to catch their balance if the trip or feel unsteady during gait [149]. This slows gait down about 30\% in people with diabetes compared to age-matched controls subjects.

\section{Summary}

In summary, for older individuals and people with diabetes there are multiple impairments in the autonomic nervous system that affect activities of daily living from very simple ones, such as response to local heat or the pressure on the feet during standing leading to increased possibilities of burns and skin damage, to more complex movements such as balance and gait which are substantially impaired in people with diabetes. Patients must be counseled during therapy, relative to these impairments, so as to protect them as they carry out their normal daily life activities.

\section{References}

[1] E. Makrantonaki, P. Schönknecht, A. M. Hossini et al., "Skin and brain age together: The role of hormones in the ageing process," Experimental Gerontology, vol. 45, no. 10, pp. 801813, 2010.

[2] E. Makrantonaki and C. C. Zouboulis, "Dermatoendocrinology: Skin Aging," Hautarzt, vol. 61, no. 6, pp. 505-510, 2010.

[3] D. L. Kellogg, C. G. Crandall, Y. Liu, N. Charkoudian, and J. M. Johnson, "Nitric oxide and cutaneous active vasodilation during heat stress in humans," Journal of Applied Physiology, vol. 85, no. 3, pp. 824-829, 1998.

[4] C. Maloney-Hinds, J. S. Petrofsky, G. Zimmerman, and D. A. Hessinger, "The role of nitric oxide in skin blood flow increases due to vibration in healthy adults and adults with type 2 diabetes," Diabetes Technology and Therapeutics, vol. 11, no. 1, pp. 39-43, 2009.

[5] D. M. Hirai, S. W. Copp, K. S. Hageman, D. C. Poole, and T. I. Musch, "Aging alters the contribution of nitric oxide to regional muscle hemodynamic control at rest and during exercise in rats," Journal of Applied Physiology, vol. 111, no. 4, pp. 989-998, 2011.

[6] J. Petrofsky, E. Lohman, S. Lee et al., "Effects of contrast baths on skin blood flow on the dorsal and plantar foot in people with type 2 diabetes and age-matched controls," 
Physiotherapy Theory and Practice, vol. 23, no. 4, pp. 189-197, 2007.

[7] M. Farage, K. Miller, and H. Maibach, Eds., Influence of Race, Gender, Age and Diabetes on the Skin Circluation. Text Book of Ageing Skin, Springer, Berlin, Germany, 2010.

[8] S. L. Carroll, S. J. Byer, D. A. Dorsey, M. A. Watson, and R. E. Schmidt, "Ganglion-specific patterns of diabetes-modulated gene expression are established in prevertebral and paravertebral sympathetic ganglia prior to the development of neuroaxonal dystrophy," Journal of Neuropathology and Experimental Neurology, vol. 63, no. 11, pp. 1144-1154, 2004.

[9] R. E. Schmidt, D. A. Dorsey, L. N. Beaudet, and R. G. Peterson, "Analysis of the Zucker Diabetic Fatty (ZDF) type 2 diabetic rat model suggests a neurotrophic role for insulin/IGF-I in diabetic autonomic neuropathy," American Journal of Pathology, vol. 163, no. 1, pp. 21-28, 2003.

[10] D. H. Damon, "Vascular-dependent effects of elevated glucose on postganglionic sympathetic neurons," American Journal of Physiology, vol. 300, no. 4, pp. H1386-H1392, 2011.

[11] A. M. Rizzo, P. Berselli, S. Zava et al., "Endogenous antioxidants and radical scavengers," Advances in Experimental Medicine and Biology, vol. 698, pp. 52-67, 2010.

[12] M. Valko, D. Leibfritz, J. Moncol, M. T. D. Cronin, M. Mazur, and J. Telser, "Free radicals and antioxidants in normal physiological functions and human disease," International Journal of Biochemistry and Cell Biology, vol. 39, no. 1, pp. 44-84, 2007.

[13] M. Valko, C. J. Rhodes, J. Moncol, M. Izakovic, and M. Mazur, "Free radicals, metals and antioxidants in oxidative stress-induced cancer," Chemico-Biological Interactions, vol. 160, no. 1, pp. 1-40, 2006.

[14] P. Samborski, D. Naskręt, A. Araszkiewicz, P. Niedźwiecki, D. Zozulińska-Ziółkiewicz, and B. Wierusz-Wysocka, "Assessment of skin autofluorescence as a marker of advanced glycation end product accumulation in type 1 diabetes," Polskie Archiwum Medycyny Wewnetrznej, vol. 121, no. 3, pp. 67-72, 2011.

[15] A. U. Ferrari, "Modifications of the cardiovascular system with aging," American Journal of Geriatric Cardiology, vol. 11, no. 1, pp. 30-34, 2002.

[16] J. B. Buse, H. N. Ginsberg, G. L. Bakris et al., "Primary prevention of cardiovascular diseases in people with diabetes mellitus: A scientific statement from the American Heart Association and the American Diabetes Association," Circulation, vol. 115, no. 1, pp. 114-126, 2007.

[17] S. M. Grundy, "Diabetes and coronary risk equivalency: What does it mean?" Diabetes Care, vol. 29, no. 2, pp. 457460, 2006.

[18] J. Petrofsky and S. Lee, "The effects of type 2 diabetes and aging on vascular endothelial and autonomic function," Medical Science Monitor, vol. 11, no. 6, pp. CR247-CR254, 2005.

[19] J. Petrofsky, S. Lee, and M. Cuneo, "Effects of aging and type 2 diabetes on resting and post occlusive hyperemia of the forearm; the impact of rosiglitazone," BMC Endocrine Disorders, vol. 5, article no. 4, 2005.

[20] D. W. Trott, J. W. Seawright, M. J. Luttrell, and C. R. Woodman, "NAD $(\mathrm{P}) \mathrm{H}$ oxidase-derived reactive oxygen species contribute to age-related impairments of endotheliumdependent dilation in rat soleus feed arteries," Journal of Applied Physiology, vol. 110, no. 5, pp. 1171-1180, 2011.

[21] R. A. Harris, J. Pedersen-White, D.-H. Guo et al., "Vitamin D3 supplementation for 16 weeks improves flow-mediated dilation in overweight African-American adults," American Journal of Hypertension, vol. 24, no. 5, pp. 557-562, 2011.

[22] R. De Jongh, G. R. M. M. Haenen, G. A. Van Koeveringe, M. Dambros, J. G. R. De Mey, and P. E. V. Van Kerrebroeck, "Oxidative stress reduces the muscarinic receptor function in the urinary bladder," Neurourology and Urodynamics, vol. 26, no. 2, pp. 302-308, 2007.

[23] E. M. Rosa, B. G. Restelatto, and V. Poyer, "Cardiovascular autonomic dysfunction in patients with diabetes mellitus type 1," Arquivos brasileiros de cardiologia, vol. 97, no. 6, pp. 541-542, 2011.

[24] N. L. Katsilambros, A. J. Boulton, N. Tentolouris, A. Kokkinos, and S. Liatis, "Autonomic neuropathy in diabetes mellitus and obesity: an update," Experimental Diabetes Research, vol. 2011, Article ID 607309, 2 pages, 2011.

[25] L. Van Nassauw, J. Bogers, E. Van Marck, and J. P. Timmermans, "Role of reactive nitrogen species in neuronal cell damage during intestinal schistosomiasis," Cell and Tissue Research, vol. 303, no. 3, pp. 329-336, 2001.

[26] J. S. Petrofsky, "The effect of type-2-diabetes-related vascular endothelial dysfunction on skin physiology and activities of daily living," Journal of Diabetes Science and Technology, vol. 5, no. 3, pp. 657-667, 2011.

[27] A. A. Bulhak, P. O. Sjöquist, C. B. Xu, L. Edvinsson, and J. Pernow, "Protection against myocardial ischaemia/reperfusion injury by PPAR- $\alpha$ activation is related to production of nitric oxide and endothelin-1," Basic Research in Cardiology, vol. 101, no. 3, pp. 244-252, 2006.

[28] G. Y. Oudit and Z. Kassiri, "Role of PI3 kinase gamma in excitation-contraction coupling and heart disease," Cardiovascular and Hematological Disorders, vol. 7, no. 4, pp. 295304, 2007.

[29] M. A. Farage, K. W. Miller, and H. I. Maibach, Textbook of Aging Skin, Springer, Berlin, Germany, 2010.

[30] L. B. Rowell, "Reflex control of the cutaneous vasculature," Journal of Investigative Dermatology, vol. 69, no. 1, pp. 154166, 1977.

[31] L. B. Rowell, "Reflex control of the circulation during exercise," International Journal of Sports Medicine, vol. 13, no. 1, pp. S25-S27, 1992.

[32] A. I. Vinik, R. Freeman, and T. Erbas, "Diabetic Autonomic Neuropathy," Seminars in Neurology, vol. 23, no. 4, pp. 365372, 2003.

[33] R. Alemzadeh, P. Palma-Sisto, E. A. Parton, and M. K. Holzum, "Continuous subcutaneous insulin infusion and multiple dose of insulin regimen display similar patterns of blood glucose excursions in pediatric type 1 diabetes," Diabetes Technology and Therapeutics, vol. 7, no. 4, pp. 587596, 2005.

[34] P. Dandona, K. Thusu, S. Cook et al., "Oxidative damage to DNA in diabetes mellitus," Lancet, vol. 347, no. 8999, pp. 444-445, 1996.

[35] L. Quagliaro, L. Piconi, R. Assaloni et al., "Intermittent high glucose enhances ICAM-1, VCAM-1 and E-selectin expression in human umbilical vein endothelial cells in culture: The distinct role of protein kinase $\mathrm{C}$ and mitochondrial superoxide production," Atherosclerosis, vol. 183, no. 2, pp. 259-267, 2005.

[36] N. Azad, N. V. Emanuele, C. Abraira et al., "The effects of intensive glycemic control on neuropathy in the VA cooperative study on type II diabetes mellitus (VA CSDM)," Journal of Diabetes and Its Complications, vol. 13, no. 5-6, pp. 307-313, 1999. 
[37] A. I. Vinik, R. E. Maser, B. D. Mitchell, and R. Freeman, "Diabetic autonomic neuropathy," Diabetes Care, vol. 26, no. 5, pp. 1553-1579, 2003.

[38] R. Pop-Busui, J. Lu, N. Lopes, and T. L. Z. Jones, "Prevalence of diabetic peripheral neuropathy and relation to glycemic control therapies at baseline in the BARI 2D cohort," Journal of the Peripheral Nervous System, vol. 14, no. 1, pp. 1-13, 2009.

[39] F. J. Cameron, S. M. Donath, and P. A. Baghurst, "Measuring glycaemic variation," Current Diabetes Reviews, vol. 6, no. 1, pp. 17-26, 2010.

[40] A. Risso, F. Mercuri, L. Quagliaro, G. Damante, and A. Ceriello, "Intermittent high glucose enhances apoptosis in human umbilical vein endothelial cells in culture," American Journal of Physiology, vol. 281, no. 5, pp. E924-E930, 2001.

[41] F. Infusino, D. Pitocco, F. Zaccardi et al., "Low glucose blood levels are associated with abnormal cardiac sympatho-vagal balance in type 2 diabetic patients with coronary artery disease," European Review for Medical and Pharmacological Sciences, vol. 14, no. 3, pp. 203-207, 2010.

[42] X. Y. Ye, Q. Tu, Z. Tong, Y. J. Weng, and Y. F. Wang, "Effects of glucose concentration fluctuation on function of cultured bovine arterial endothelial cells," Zhonghua xin xue guan bing za zhi, vol. 38, no. 3, pp. 264-267, 2010.

[43] J. Kostolanská, V. Jakuš, L. Barák, and A. Staníková, "Impact of long-term glycemic control on changes of lipid profile in children and adolescents with 1 type diabetes mellitus," Vnitrni Lekarstvi, vol. 57, no. 6, pp. 533-539, 2011.

[44] D. K. Singh, P. Winocour, and K. Farrington, "Oxidative stress in early diabetic nephropathy: fueling the fire," Nature Reviews Endocrinology, vol. 7, no. 3, pp. 176-184, 2011.

[45] J. H. Lee, T. Palaia, and L. Ragolia, "Impaired insulinmediated vasorelaxation in diabetic Goto-Kakizaki rats is caused by impaired Akt phosphorylation," American Journal of Physiology, vol. 296, no. 2, pp. C327-C338, 2009.

[46] R. J. Woodman, D. A. Playford, and G. F. Watts, "Basal production of nitric oxide (NO) and non-NO vasodilators in the forearm microcirculation in Type 2 diabetes: Associations with blood pressure and HDL cholesterol," Diabetes Research and Clinical Practice, vol. 71, no. 1, pp. 59-67, 2006.

[47] M. A. Potenza, S. Gagliardi, C. Nacci, M. R. Carratu, and M. Montagnani, "Endothelial dysfunction in diabetes: From mechanisms to therapeutic targets," Current Medicinal Chemistry, vol. 16, no. 1, pp. 94-112, 2009.

[48] F. Giacco and M. Brownlee, "Oxidative stress and diabetic complications," Circulation Research, vol. 107, no. 9, pp. 1058-1070, 2010.

[49] A. A. Bulhak, C. Jung, C. G. Östenson, J. O. Lundberg, P. O. Sjoquist, and J. Pernow, "PPAR- $\alpha$ activation protects the type 2 diabetic myocardium against ischemia-reperfusion injury: Involvement of the PI3-kinase/Akt and NO pathway," American Journal of Physiology, vol. 296, no. 3, pp. H719H727, 2009.

[50] S. Gogg, U. Smith, and P. A. Jansson, "Increased MAPK activation and impaired insulin signaling in subcutaneous microvascular endothelial cells in type 2 diabetes: The role of endothelin-1," Diabetes, vol. 58, no. 10, pp. 2238-2245, 2009.

[51] C. de Wit, M. Boettcher, and V. J. Schmidt, "Signaling across myoendothelial gap junctions-fact or fiction?" Cell Communication and Adhesion, vol. 15, no. 3, pp. 231-245, 2008.

[52] P. K. Gupta, J. Subramani, M. D. M. Leo et al., "Role of voltage-dependent potassium channels and myo-endothelial gap junctions in 4-aminopyridine-induced inhibition of acetylcholine relaxation in rat carotid artery," European Journal of Pharmacology, vol. 591, no. 1-3, pp. 171-176, 2008.

[53] C. R. Triggle, M. Hollenberg, T. J. Anderson et al., "The endothelium in health and disease-a target for therapeutic intervention," Journal of Smooth Muscle Research, vol. 39, no. 6, pp. 249-267, 2003.

[54] T. Sato, R. Haimovici, R. Kao, A. F. Li, and S. Roy, "Downregulation of connexin 43 expression by high glucose reduces gap junction activity in microvascular endothelial cells," Diabetes, vol. 51, no. 5, pp. 1565-1571, 2002.

[55] D. Lawson and J. S. Petrofsky, "A randomized control study on the effect of biphasic electrical stimulation in a warm room on skin blood flow and healing rates in chronic wounds of patients with and without diabetes," Medical Science Monitor, vol. 13, no. 6, pp. CR258-CR263, 2007.

[56] J. Petrofsky, S. Lee, and M. Cuneo, "Effects of aging and type 2 diabetes on resting and post occlusive hyperemia of the forearm; the impact of rosiglitazone," BMC Endocrine Disorders, vol. 5, article no. 4, 2005.

[57] J. S. Petrofsky, N. Focil, M. Prowse et al., "Autonomic stress and balance-the impact of age and diabetes," Diabetes Technology \& Therapeutics, vol. 12, no. 6, pp. 475-481, 2010.

[58] J. Petrofsky, S. Lee, and M. Cuneo-Libarona, "The impact of rosiglitazone on heat tolerance in patients with Type 2 Diabetes," Medical Science Monitor, vol. 11, no. 12, pp. CR562-CR569, 2005.

[59] J. S. Petrofsky, S. Lee, C. Patterson, M. Cole, and B. Stewart, "Sweat production during global heating and during isometric exercise in people with diabetes," Medical Science Monitor, vol. 11, no. 11, pp. CR515-CR521, 2005.

[60] S. H. Horowitz, "Recent clinical advances in diabetic polyneuropathy," Current Opinion in Anaesthesiology, vol. 19, no. 5, pp. 573-578, 2006.

[61] B. Sridhar, N. Haleagrahara, R. Bhat, A. B. Kulur, S. Avabratha, and P. Adhikary, "Increase in the heart rate variability with deep breathing in diabetic patients after 12month exercise training," Tohoku Journal of Experimental Medicine, vol. 220, no. 2, pp. 107-113, 2010.

[62] I. G. Obrosova, "Diabetic painful and insensate neuropathy: pathogenesis and potential treatments," Neurotherapeutics, vol. 6, no. 4, pp. 638-647, 2009.

[63] J. Petrofsky, D. Paluso, D. Anderson et al., "The ability of different areas of the skin to absorb heat from a locally applied heat source: the impact of diabetes," Diabetes Technology and Therapeutics, vol. 13, no. 3, pp. 365-372, 2011.

[64] J. Petrofsky, D. Paluso, D. Anderson et al., "The contribution of skin blood flow in warming the skin after the application of local heat; the duality of the Pennes heat equation," Medical Engineering and Physics, vol. 33, no. 3, pp. 325-329, 2011.

[65] J. S. Petrofsky, D. Lawson, L. Berk, and H. Suh, "Enhanced healing of diabetic foot ulcers using local heat and electrical stimulation for 30 min three times per week," Journal of Diabetes, vol. 2, no. 1, pp. 41-46, 2010.

[66] I. Fredriksson, M. Larsson, F. H. Nyström, T. Länne, C. J. Östgren, and T. Strömberg, "Reduced arteriovenous shunting capacity after local heating and redistribution of baseline skin blood flow in type 2 diabetes assessed with velocityresolved quantitative laser Doppler flowmetry," Diabetes, vol. 59, no. 7, pp. 1578-1584, 2010.

[67] M. Noble, D. Voegeli, and G. F. Clough, "A comparison of cutaneous vascular responses to transient pressure loading in smokers and nonsmokers," Journal of Rehabilitation Research and Development, vol. 40, no. 3, pp. 283-288, 2003. 
[68] Y. K. Jan, D. M. Brienza, M. J. Geyer, and P. Karg, "Waveletbased spectrum analysis of sacral skin blood flow response to alternating pressure," Archives of Physical Medicine and Rehabilitation, vol. 89, no. 1, pp. 137-145, 2008.

[69] J. S. Petrofsky, G. S. Bains, M. Prowse et al., "The influence of age and diabetes on the skin blood flow response to local pressure," Medical Science Monitor, vol. 15, no. 7, pp. CR325CR331, 2009.

[70] G. Nakagami, Y. Sari, T. Nagase, S. Iizaka, Y. Ohta, and H. Sanada, "Evaluation of the usefulness of skin blood flow measurements by laser speckle flowgraphy in pressureinduced ischemic wounds in rats," Annals of Plastic Surgery, vol. 64, no. 3, pp. 351-354, 2010.

[71] K. McLellan, J. S. Petrofsky, G. Bains, G. Zimmerman, M. Prowse, and S. Lee, "The effects of skin moisture and subcutaneous fat thickness on the ability of the skin to dissipate heat in young and old subjects, with and without diabetes, at three environmental room temperatures," Medical Engineering and Physics, vol. 31, no. 2, pp. 165-172, 2009.

[72] K. McLellan, J. S. Petrofsky, G. Zimmerman, M. Prowse, G. Bains, and S. Lee, "Multiple stressors and the response of vascular endothelial cells: The effect of aging and diabetes," Diabetes Technology and Therapeutics, vol. 11, no. 2, pp. 7379, 2009.

[73] M. Bharara, J. Schoess, A. Nouvong, and D. G. Armstrong, "Wound inflammatory index: a "proof of concept" study to assess wound healing trajectory," Journal of diabetes science and technology, vol. 4, no. 4, pp. 773-779, 2010.

[74] J. S. Petrofsky, K. McLellan, M. Prowse, G. Bains, L. Berk, and S. Lee, "The effect of body fat, aging, and diabetes on vertical and shear pressure in and under a waist belt and its effect on skin blood flow," Diabetes Technology and Therapeutics, vol. 12, no. 2, pp. 153-160, 2010.

[75] K. McLellan, J. S. Petrofsky, G. Zimmerman et al., "The influence of environmental temperature on the response of the skin to local pressure: the impact of aging and diabetes," Diabetes technology \& therapeutics, vol. 11, no. 12, pp. 791798, 2009.

[76] D. Santos-García, M. Blanco, J. Serena, M. Rodríguez-Yáñez, R. Leira, and J. Castillo, "Impaired brachial flow-mediated dilation is a predictor of a new-onset vascular event after stroke," Cerebrovascular Diseases, vol. 32, no. 2, pp. 155-162, 2011.

[77] B. J. Wong, B. W. Wilkins, L. A. Holowatz, and C. T. Minson, "Nitric oxide synthase inhibition does not alter the reactive hyperemic response in the cutaneous circulation," Journal of Applied Physiology, vol. 95, no. 2, pp. 504-510, 2003.

[78] D. L. Kellogg, Y. Liu, I. F. Kosiba, and D. O’Donnell, "Role of nitric oxide in the vascular effects of local warming of the skin in humans," Journal of Applied Physiology, vol. 86, no. 4, pp. 1185-1190, 1999.

[79] C. T. Minson, L. T. Berry, and M. J. Joyner, "Nitric oxide and neurally mediated regulation of skin blood flow during local heating," Journal of Applied Physiology, vol. 91, no. 4, pp. 1619-1626, 2001.

[80] K. Sauerstein, M. Klede, M. Hilliges, and M. Schmelz, "Electrically evoked neuropeptide release and neurogenic inflammation differ between rat and human skin," Journal of Physiology, vol. 529, no. 3, pp. 803-810, 2000.

[81] B. Namer, A. Bickel, H. Krämer, F. Birklein, and M. Schmelz, "Chemically and electrically induced sweating and flare reaction," Autonomic Neuroscience: Basic and Clinical, vol. 114, no. 1-2, pp. 72-82, 2004.
[82] J. S. Petrofsky, A. M. Al-Malty, and M. Prowse, "Relationship between multiple stimuli and skin blood flow," Medical Science Monitor, vol. 14, no. 8, pp. CR399-CR405, 2008.

[83] H. H. Pennes, "Analysis of tissue and arterial blood temperatures in the resting human forearm," Journal of Applied Physiology, vol. 1, no. 2, pp. 93-122, 1948.

[84] A. A. H. S. Al-Janabi, "Potential activity of the purine compounds caffeine and aminophylline on bacteria," Journal of Global Infectious Diseases, vol. 3, no. 2, pp. 133-137, 2011.

[85] G. Y. Oudit, M. G. Trivieri, N. Khaper, P. P. Liu, and P. H. Backx, "Role of L-type Ca2 ${ }^{+}$channels in iron transport and iron-overload cardiomyopathy," Journal of Molecular Medicine, vol. 84, no. 5, pp. 349-364, 2006.

[86] R. L. Baylie and J. E. Brayden, "TRPV channels and vascular function," Acta Physiologica, vol. 203, no. 1, pp. 99-116, 2011.

[87] H. Watanabe, J. Vriens, S. H. Suh, C. D. Benham, G. Droogmans, and B. Nilius, "Heat-evoked activation of TRPV4 channels in a HEK293 cell expression system and in native mouse aorta endothelial cells," Journal of Biological Chemistry, vol. 277, no. 49, pp. 47044-47051, 2002.

[88] S. Brunton, "Current face of acute otitis media: Microbiology and prevalence resulting from widespread use of heptavalent pneumococcal conjugate vaccine," Clinical Therapeutics, vol. 28, no. 1, pp. 118-123, 2006.

[89] J. Petrofsky, N. Goraksh, F. Alshammari et al., "The ability of the skin to absorb heat; the effect of repeated exposure and age," Medical Science Monitor, vol. 17, no. 1, pp. CR1-CR8, 2011.

[90] J. Petrofsky, S. Gunda, C. Raju et al., "Impact of hydrotherapy on skin blood flow: How much is due to moisture and how much is due to heat?" Physiotherapy Theory and Practice, vol. 26, no. 2, pp. 107-112, 2010.

[91] J. Petrofsky, H. Lee, M. Trivedi et al., "The influence of aging and diabetes on heat transfer characteristics of the skin to a rapidly applied heat source," Diabetes Technology and Therapeutics, vol. 12, no. 12, pp. 1003-1010, 2010.

[92] A. Tagliabue, D. Terracina, H. Cena, G. Turconi, E. Lanzola, and C. Montomoli, "Coffee induced thermogenesis and skin temperature," International Journal of Obesity, vol. 18, no. 8, pp. 537-541, 1994.

[93] L. Gattinoni, M. Bombino, P. Pelosi et al., "Lung structure and function in different stages of severe adult respiratory distress syndrome," Journal of the American Medical Association, vol. 271, no. 22, pp. 1772-1779, 1994.

[94] S. Menard, P. Squicciarini, A. Luini et al., "Immunodetection of bone marrow micrometastases in breast carcinoma patients and its correlation with primary tumour prognostic features," British Journal of Cancer, vol. 69, no. 6, pp. 11261129, 1994.

[95] J. Petrofsky, "A method of measuring the interaction between skin temperature and humidity on skin vascular endothelial function in people with diabetes," Journal of Medical Engineering and Technology, vol. 35, no. 6-7, pp. 330-337, 2011.

[96] J. Petrofsky, F. Alshahmmari, J. Eun Yim et al., "The interrealtionship between locally applied heat, ageing and skin blood flow on heat transfer into and from the skin," Journal of Medical Engineering and Technology, vol. 35, no. 5, pp. 262-274, 2011.

[97] J. S. Petrofsky, K. McLellan, G. S. Bains et al., "Skin heat dissipation: The influence of diabetes, skin thickness, and subcutaneous fat thickness," Diabetes Technology and Therapeutics, vol. 10, no. 6, pp. 487-493, 2008.

[98] K. McLellan, J. S. Petrofsky, G. Bains, G. Zimmerman, M. Prowse, and S. Lee, "The effects of skin moisture and 
subcutaneous fat thickness on the ability of the skin to dissipate heat in young and old subjects, with and without diabetes, at three environmental room temperatures," Medical Engineering and Physics, vol. 31, no. 2, pp. 165-172, 2009.

[99] J. Petrofsky, F. Alshahmmari, J. Eun Yim et al., "The interrealtionship between locally applied heat, ageing and skin blood flow on heat transfer into and from the skin," Journal of Medical Engineering and Technology, vol. 35, no. 5, pp. 262-274, 2011.

[100] J. Petrofsky, D. Paluso, D. Anderson et al., "The ability of different areas of the skin to absorb heat from a locally applied heat source: the impact of diabetes," Diabetes Technology and Therapeutics, vol. 13, no. 3, pp. 365-372, 2011.

[101] R. M. Jose, R. Vidyadharan, D. K. Roy, and M. Erdmann, "Hot water bottles and diabetic patients-a cautionary tale," British Journal of General Practice, vol. 55, no. 512, pp. 222223, 2005.

[102] M. Tagliabue, T. C. Casella, G. E. Zincone, R. Fumagalli, and E. Salvini, "CT and chest radiography in the evaluation of adult respiratory distress syndrome," Acta Radiologica, vol. 35, no. 3, pp. 230-234, 1994.

[103] H. Mayaudon, P. O. Miloche, and B. Bauduceau, "A new simple method for assessing sudomotor function: relevance in type 2 diabetes," Diabetes and Metabolism, vol. 36, no. 6, pp. 450-454, 2010.

[104] J. Petrofsky, E. Lohman III, S. Lee et al., "The influence of alterations in room temperature on skin blood flow during contrast baths in patients with diabetes," Medical Science Monitor, vol. 12, no. 7, pp. CR290-CR295, 2006.

[105] D. Morelli, E. Villa, E. Tagliabue et al., "Relevance of antibody valency in EGF receptor modulation," Scandinavian Journal of Immunology, vol. 39, no. 5, pp. 453-458, 1994.

[106] J. Petrofsky, E. Lohman III, S. Lee et al., "Effects of contrast baths on skin blood flow on the dorsal and plantar foot in people with type 2 diabetes and age-matched controls," Physiotherapy Theory and Practice, vol. 23, no. 4, pp. 189-197, 2007.

[107] J. Petrofsky, E. Lohman, S. Lee et al., "The influence of alterations in room temperature on skin blood flow during contrast baths in patients with diabetes," Medical Science Monitor, vol. 12, no. 7, pp. CR290-CR295, 2006.

[108] R. K. Anderson and W. L. Kenney, "Effect of age on heatactivated sweat gland density and flow during exercise in dry heat," Journal of Applied Physiology, vol. 63, no. 3, pp. 10891094, 1987.

[109] L. B. Rowell, "Cardiovascular aspects of human thermoregulation," Circulation Research, vol. 52, no. 4, pp. 367-379, 1983.

[110] W. L. Kenney and R. K. Anderson, "Responses of older and younger women to exercise in dry and humid heat without fluid replacement," Medicine and Science in Sports and Exercise, vol. 20, no. 2, pp. 155-160, 1988.

[111] Y. Inoue, "Longitudinal effects of age on heat-activated sweat gland density and output in healthy active older men," European Journal of Applied Physiology and Occupational Physiology, vol. 74, no. 1-2, pp. 72-77, 1996.

[112] C. G. Tankersley, J. Smolander, W. L. Kenney, and S. M. Fortney, "Sweating and skin blood flow during exercise: Effects of age and maximal oxygen uptake," Journal of Applied Physiology, vol. 71, no. 1, pp. 236-242, 1991.

[113] M. L. Savio, C. Rossi, P. Fusi, S. Tagliabue, and M. L. Pacciarini, "Detection and identification of Leptospira interrogans serovars by PCR coupled with restriction endonuclease analysis of amplified DNA," Journal of Clinical Microbiology, vol. 32, no. 4, pp. 935-941, 1994.

[114] M. Caputi, G. Casari, S. Guenzi et al., "A novel bipartite splicing enhancer modulates the differential processing of the human fibronectin EDA exon," Nucleic Acids Research, vol. 22, no. 6, pp. 1018-1022, 1994.

[115] M. Anburajan, S. Sivanandam, S. Bidyarasmi, B. Venkatraman, M. Menaka, and B. Raj, "Changes of skin temperature of parts of the body and serum asymmetric dimethylarginine (ADMA) in type-2 diabetes mellitus Indian patients," in Proceedings of the Annual International Conference of the IEEE Engineering in Medicine and Biology Society (EMBS '11), pp. 6254-6259, August-September 2011.

[116] R. D. Hoeldtke, K. D. Bryner, and K. Vandyke, "Oxidative stress and autonomic nerve function in early type 1 diabetes," Clinical Autonomic Research, vol. 21, no. 1, pp. 19-28, 2011.

[117] A. M. Vincent, J. W. Russell, P. Low, and E. L. Feldman, "Oxidative stress in the pathogenesis of diabetic neuropathy," Endocrine Reviews, vol. 25, no. 4, pp. 612-628, 2004.

[118] K. McLellan, J. S. Petrofsky, G. Zimmerman, M. Prowse, G. Bains, and S. Lee, "Multiple stressors and the response of vascular endothelial cells: The effect of aging and diabetes," Diabetes Technology and Therapeutics, vol. 11, no. 2, pp. 7379, 2009.

[119] J. C. Philips, M. Marchand, and A. J. Scheen, "Squatting, a posture test for studying cardiovascular autonomic neuropathy in diabetes," Diabetes and Metabolism, vol. 37, no. 6, pp. 489-496, 2011.

[120] J.-C. Philips and A. J. Scheen, "Squatting test: a posture to study and counteract cardiovascular abnormalities associated with autonomic dysfunction," Autonomic Neuroscience: Basic and Clinical, vol. 162, no. 1-2, pp. 3-9, 2011.

[121] B. P. Grubb and D. Kosinski, "Tilt table testing: Concepts and limitations," Pacing and Clinical Electrophysiology, vol. 20, no. 3, pp. 781-787, 1997.

[122] J. S. Petrofsky, C. Besonis, D. Rivera, E. Schwab, and S. Lee, "Impairment in orthostatic tolerance during heat exposure in individuals with Type I and Type II diabetes," Medical Science Monitor, vol. 11, no. 4, pp. CR153-CR159, 2005.

[123] D. M. Keller, D. A. Low, S. L. Davis, J. Hastings, and C. G. Crandall, "Skin surface cooling improves orthostatic tolerance following prolonged head-down bed rest," Journal of Applied Physiology, vol. 110, no. 6, pp. 1592-1597, 2011.

[124] A. Fedorowski, L. Stavenow, B. Hedblad, G. Berglund, P. M. Nilsson, and O. Melander, "Orthostatic hypotension predicts all-cause mortality and coronary events in middleaged individuals (The Malmo Preventive Project)," European Heart Journal, vol. 31, no. 1, pp. 85-91, 2010.

[125] C. Murrell, J. D. Cotter, K. George et al., "Influence of age on syncope following prolonged exercise: Differential responses but similar orthostatic intolerance," Journal of Physiology, vol. 587, no. 24, pp. 5959-5969, 2009.

[126] R. E. Maser, B. D. Mitchell, A. I. Vinik, and R. Freeman, “The association between cardiovascular autonomic neuropathy and mortality in individuals with diabetes a meta-analysis," Diabetes Care, vol. 26, no. 6, pp. 1895-1901, 2003.

[127] Z. Q. Lin et al., "Prevalence and clinical characteristics of orthostatic hypotension in the elderly and retired population," Zhonghua xin xue guan bing za zhi, vol. 39, no. 5, pp. 457-662, 2011.

[128] K. M. Madden, C. K. Lockhart, T. F. Potter, D. J. Cuff, and G. S. Meneilly, "Short-term aerobic exercise reduces nitroglycerin-induced orthostatic intolerance in older adults 
with type 2 diabetes," Journal of Cardiovascular Pharmacology, vol. 57, no. 6, pp. 666-671, 2011.

[129] J. S. Petrofsky, N. Focil, M. Prowse et al., "Autonomic stress and balance-the impact of age and diabetes," Diabetes Technology \& Therapeutics, vol. 12, no. 6, pp. 475-481, 2010.

[130] D. Nunan, G. R. H. Sandercock, and D. A. Brodie, "A quantitative systematic review of normal values for shortterm heart rate variability in healthy adults," Pacing and Clinical Electrophysiology, vol. 33, no. 11, pp. 1407-1417, 2010.

[131] D. Nunan, D. G. Jakovljevic, G. Donovan, L. D. Singleton, G. R. H. Sandercock, and D. A. Brodie, "Resting autonomic modulations and the heart rate response to exercise," Clinical Autonomic Research, vol. 20, no. 4, pp. 213-221, 2010.

[132] J. Petrofsky, S. Lee, M. Cuneo-Libarona, and P. Apodaca, "The effect of rosiglitazone on orthostatic tolerance during heat exposure in individuals with type II diabetes," Diabetes Technology and Therapeutics, vol. 9, no. 4, pp. 377-386, 2007.

[133] J. S. Petrofsky, C. Besonis, D. Rivera, E. Schwab, and S. Lee, "Impairment in orthostatic tolerance during heat exposure in individuals with Type I and Type II diabetes," Medical Science Monitor, vol. 11, no. 4, pp. CR153-CR159, 2005.

[134] V. Campanucci, A. Krishnaswamy, and E. Cooper, "Diabetes depresses synaptic transmission in sympathetic ganglia by inactivating $\mathrm{nAChRs}$ through a conserved intracellular cysteine residue," Neuron, vol. 66, no. 6, pp. 827-834, 2010.

[135] J. C. Philips, M. Marchand, and A. J. Scheen, "Pulse pressure and cardiovascular autonomic neuropathy according to duration of type 1 diabetes," Diabetes/Metabolism Research and Reviews, vol. 25, no. 5, pp. 442-451, 2009.

[136] G. F. DiBona, "Central angiotensin modulation of baroreflex control of renal sympathetic nerve activity in the rat: influence of dietary sodium," Acta Physiologica Scandinavica, vol. 177, no. 3, pp. 285-289, 2003.

[137] J. Cui, M. Shibasaki, D. A. Low, D. M. Keller, S. L. Davis, and C. G. Crandall, "Muscle sympathetic responses during orthostasis in heat-stressed individuals," Clinical Autonomic Research, vol. 21, no. 6, pp. 381-387, 2011.

[138] J. Tagliabue, "A church-state issue in Italy: doctors' role in birth control," The New York Times, p. A8, 1994.

[139] C. H. Song, J. S. Petrofsky, S. W. Lee, K. J. Lee, and J. E. Yim, "Effects of an exercise program on balance and trunk proprioception in older adults with diabetic neuropathies," Diabetes Technology and Therapeutics, vol. 13, no. 8, pp. 803811, 2011.

[140] J. S. Petrofsky, B. Stewart, C. Patterson, M. Cole, A. Al Malty, and S. Lee, "Cardiovascular responses and endurance during isometric exercise in patients with Type 2 diabetes compared to control subjects," Medical Science Monitor, vol. 11, no. 10, pp. CR470-CR477, 2005.

[141] J. S. Petrofsky and S. Lee, "The impact of rosiglitazone on cardiovascular responses and endurance during isometric exercise in patients with Type 2 Diabetes," Medical Science Monitor, vol. 12, no. 1, pp. CR21-CR26, 2006.

[142] J. S. Petrofsky and M. Laymon, "The effect of ageing in spinal cord injured humans on the blood pressure and heart rate responses during fatiguing isometric exercise," European Journal of Applied Physiology, vol. 86, no. 6, pp. 479-486, 2002.

[143] J. Petrofsky, M. Prowse, W. Remigio et al., "The use of an isometric handgrip test to show autonomic damage in people with diabetes," Diabetes Technology and Therapeutics, vol. 11, no. 6, pp. 361-368, 2009.
[144] J. S. Petrofsky, R. L. Burse, and A. R. Lind, "Comparison of physiological responses of women and men to isometric exercise," Journal of Applied Physiology, vol. 38, no. 5, pp. 863868, 1975.

[145] J. S. Petrofsky, M. Cuneo, S. Lee, E. Johnson, and E. Lohman, "Correlation between gait and balance in people with and without Type 2 diabetes in normal and subdued light," Medical Science Monitor, vol. 12, no. 7, pp. CR273-CR281, 2006.

[146] J. S. Petrofsky, "Thermoregulatory stress during rest and exercise in heat in patients with a spinal cord injury," European Journal of Applied Physiology and Occupational Physiology, vol. 64, no. 6, pp. 503-507, 1992.

[147] J. S. Petrofsky and M. Laymon, "Pulmonary Function in people with spinal cord injury," Journal of Neurological and Orthopaedic Medicine and Surgery, vol. 22, pp. 16-21, 2002.

[148] J. S. Petrofsky, M. Cuneo, S. Lee, E. Johnson, and E. Lohman, "Correlation between gait and balance in people with and without Type 2 diabetes in normal and subdued light," Medical Science Monitor, vol. 12, no. 7, pp. CR273-CR281, 2006.

[149] J. S. Petrofsky, S. Lee, and M. L. Cuneo, "Gait characteristics in patients with type 2 diabetes; improvement after administration of rosiglitazone," Medical Science Monitor, vol. 11, no. 6, pp. PI43-PI51, 2005. 


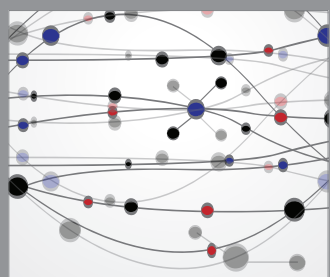

The Scientific World Journal
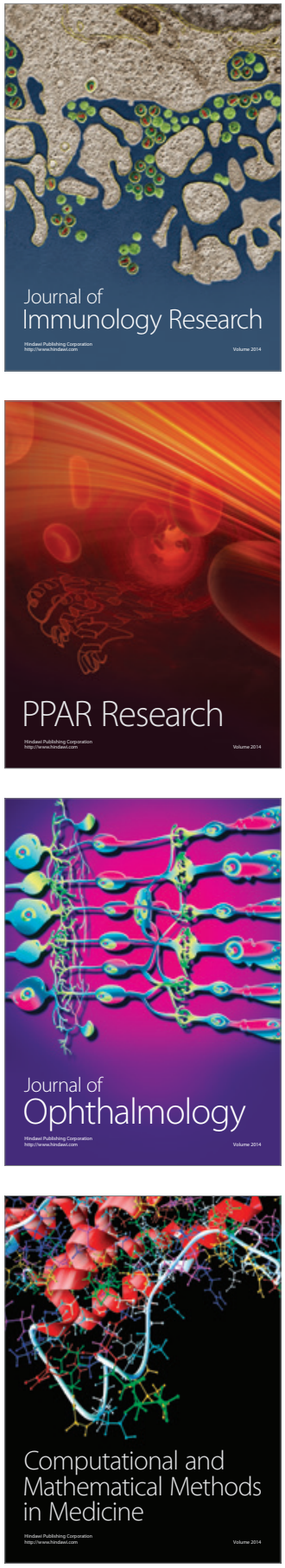

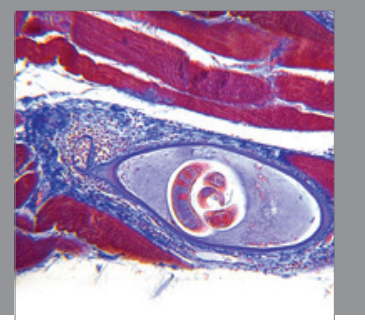

Gastroenterology

Research and Practice
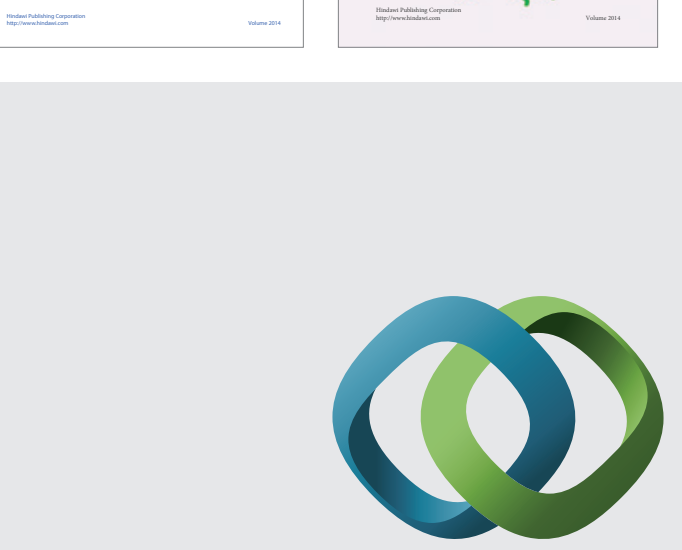

\section{Hindawi}

Submit your manuscripts at

http://www.hindawi.com
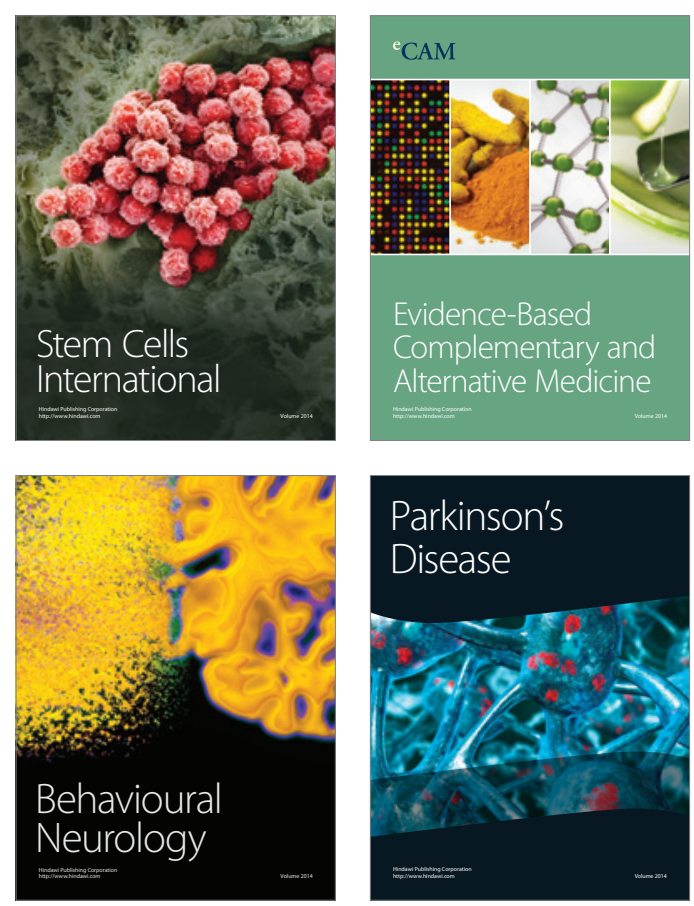

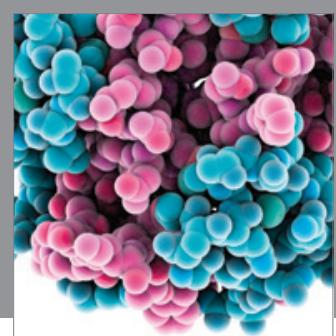

Journal of
Diabetes Research

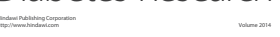

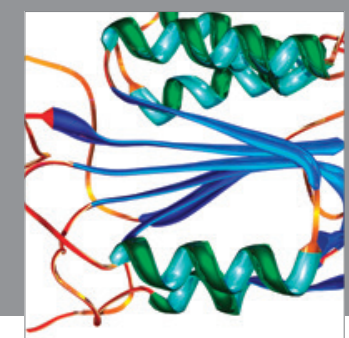

Disease Markers
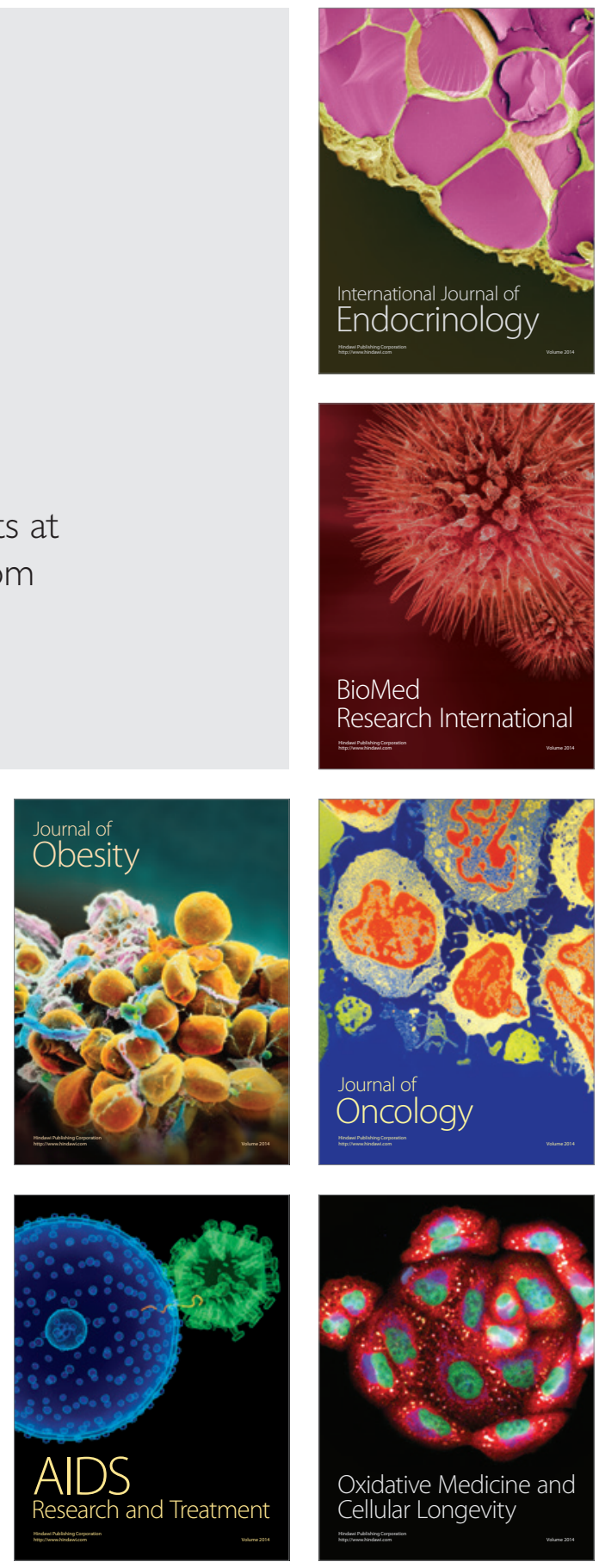